\title{
Thermal model of multilayer structure for NDT thermal parameters evaluation
}

\author{
by G. Gralewicz ${ }^{*}$, G. Owczarek ${ }^{*}$, T. Światczak ${ }^{\star *}$, B. Więcek
}

* Department of Personal Protective Equipment, Central Institute for Labour Protection - National Research Institute, Łódź, Poland, grgra@ciop.lodz.pl ** Institute of Electronics, Technical University of Łódź, Łódź, Poland, wiecek@mail.p.lodz.pl

\begin{abstract}
This paper presents the study on the mechanism of heat transport in multilayer solid body with the assumption that the heat transfer proceeds with the aid of thermal conductivity. It presents a test conducted with lock-in thermography on multilayer structure with implanted defect. The structure is made from materials of different thermal conductivity k. Different layers of tested structure described by thermal resistance and thermal capacity create supplementary circuit. The model contains the elements of the reactance character and can be used not only in qualification of static schedule of temperature, but also in investigation of transient processes.
\end{abstract}

\section{Introduction}

The fundamental laws of conduction, convection and radiation can be associated with fundamental laws of electricity. Heat transfer problems can be associated with electric circuits for simpler and solving. These associations, which work in both homogenous and multilayer structure, are based on the following similarity (Nowakowski, 2001):

$$
q=\frac{\Delta T}{R_{t h}} \leftrightarrow \quad i=\frac{\Delta V}{R}
$$

where: $i$ current in amperes $(A), \Delta V$ voltage difference in volts $(V)$, and $R$, electrical resistance in ohms $(\Omega)$. $R_{t h}$ thermal resistance $\left({ }^{0} \mathrm{~K} W^{1}\right), C_{t h}$ thermal capacity $\left(J K^{1}\right)$. Thermal problems can be converted to their electrical analog, for which practical methods are deployed for solving. Electrical analogy shown in figure 1.

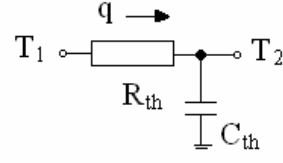

$$
\Delta \mathrm{T}=\mathrm{T}_{1}-\mathrm{T}_{2}
$$

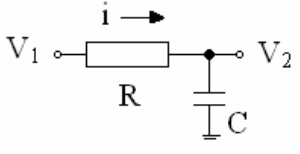

$$
\Delta \mathrm{V}=\mathrm{V}_{1}-\mathrm{V}_{2}
$$

Fig. 1. Electrical analogy 


\section{The heat transfer modes for thermal resistance}

In practical situations, combinations of conduction, convection and radiation do occur. Following our analysis of heat transfer mechanisms, we can derive expressions for $R_{\text {th }}$ lists them (Table 1.).

Table 1. The heat transfer modes for thermal resistance (Maldague, 2001)

\begin{tabular}{|c|c|c|}
\hline $\begin{array}{c}\text { Heat } \\
\text { transfer model }\end{array}$ & Thermal resistance $\left[\mathrm{Jm}^{-3} \mathrm{~K}^{-1}\right]$ & $\begin{array}{c}\text { Thermal } \\
\text { capacity }\left[\mathrm{m}^{2} \mathrm{KW}^{-1}\right]\end{array}$ \\
\hline Conduction & $R_{t h}=\frac{L}{k S}$ & \multirow{3}{*}{$C_{t h}=\rho V c_{w}$} \\
\hline Radiation & 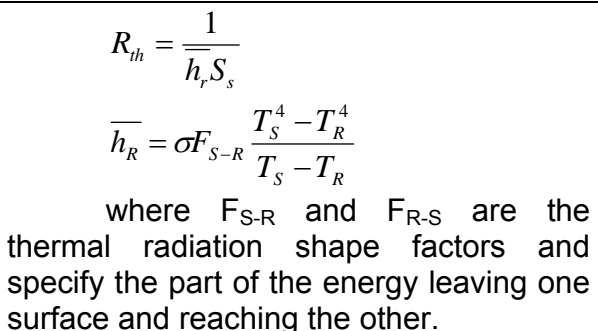 & \\
\hline Convection & $R_{t h}=\frac{1}{\bar{h} S}$ & \\
\hline
\end{tabular}

\section{Electrical model of homogenous structure}

Lets first consider the classical example of a semi-infinite structure of thickness $L$ with fixed conditions at border, $T(x=0)=T_{1}$ and $T(x=L)=T_{2}$. In this case, a semi-infinite structure is a structure that is very large with respect to its thickness, so that edges effects that would add another dimension in this heat transfer problem can be neglected. As evidence suggests, due to uniform structure property (mainly, thermal conductivity), temperature distribution is linear. It is obtained by differentiation of the first law of thermodynamics:

$$
\begin{gathered}
\frac{d}{d x}\left(-k S_{x} \frac{d T}{d x}\right)=0 \\
\frac{d^{2} T}{d x}=0 \quad T(0)=T_{1} \text { and } T(L)=T_{2}
\end{gathered}
$$

Finally: $q_{x}=\frac{k S_{x}}{L} \Delta T$ and thus $R=\frac{\Delta T}{q_{x}}=\frac{L}{k S}$. Electrical analogy shown in figure 2 . 
http://dx.doi.org/10.21611/qirt.2006.076

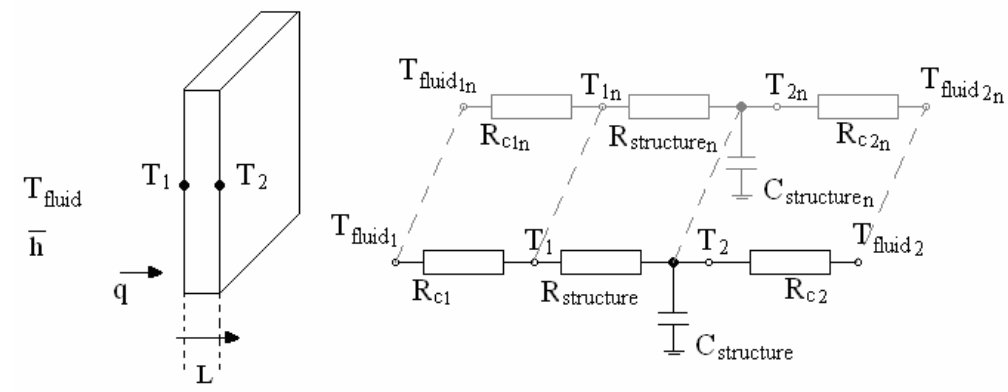

Fig. 2. Electrical model of homogenous structure

Solution for electrical model (Figure 2) is:

$$
R_{\text {structure }}=\frac{L}{k S}, R_{c}=\frac{1}{\bar{h} S}, R_{\text {total }}=R_{c 1}+R_{\text {structure }}+R_{c 2} \text { and } C_{\text {th }}=\rho V c_{w}
$$

\section{Electrical model of multilayer structure}

Let us consider a multilayer structure (structur1 - air - structure 2).

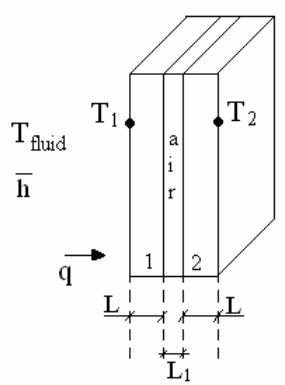

$\mathrm{L}_{1} \ll<\mathrm{L}$

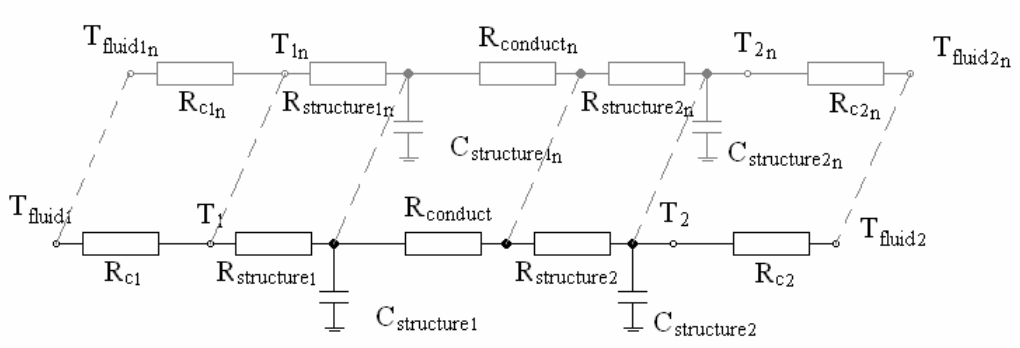

Fig. 3. Electrical model of multilayer structure

Here again an electrical analogy eases the computations. Let's first calculate the added thermal resistors $R_{\text {conduc }}$.

$$
R_{\text {conduc }}=\frac{L}{k S}
$$

Using the resistor configuration formulas, we compute $R_{\text {total }}$ as follows:

$$
R_{\text {total }}=R_{c 1}+R_{\text {structure } 1}+R_{\text {conduc }}+R_{\text {structure } 2}+R_{c 2} \text { and } C_{\text {th }}=\rho V c_{w}
$$




\section{Periodic excitation - electrical model}

Periodically varying heat flux (amplitude $40 \mathrm{mV}$ and phase 0 ) was delivered to the front side of the structure of the thickness $L$ as shown in Fig.4. The structure was examined at different modulation frequencies ranging from $1 \mathrm{~m} \mathrm{~Hz}$ to $10 \mathrm{~Hz}$. As an exemplary structure to verify the correctness of the approach we consider thin films of teflon and epoxy placed in the carbon-fiber-reinforced-plastic (CFRP) (Gralewicz 2005),

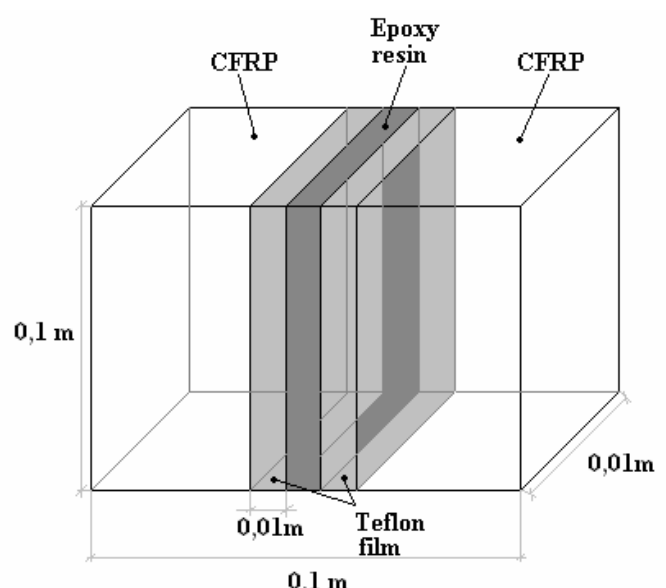

Fig. 4. Multilayer structure

where convection is defined to get real condition of energy dissipation to the ambient. The heat transfer in the solid is expressed as:

$$
\frac{\partial^{2} T}{\partial^{2} x}-\frac{\rho c}{\lambda} \frac{\partial T}{\partial t}=0
$$

Material constants used for calculation electrical model shown table 2.

Tab. 2. Material constants used for calculation electrical model (Bai 2001)

\begin{tabular}{|r|c|c|c|}
\hline & $\begin{array}{c}\text { Density } \\
\left(\mathrm{kg} \mathrm{m}^{-3}\right)\end{array}$ & $\begin{array}{c}\text { Thermal } \\
\text { conductivity } \\
\left(\mathrm{W} \mathrm{m}^{-1} \mathrm{~K}^{-1}\right)\end{array}$ & $\begin{array}{c}\text { Specific } \\
\text { heat } \\
\left(\mathrm{J} \mathrm{kg}^{-1} \mathrm{~K}^{-1}\right)\end{array}$ \\
\hline CFRP & 1600 & 0.67 & 1200 \\
\hline Teflon & 2150 & 0.209 & 1100 \\
\hline $\begin{array}{c}\text { Epoxy } \\
\text { resin }\end{array}$ & 1300 & 0.2 & 1700 \\
\hline
\end{tabular}

Assume for the investigations: environment temperature was $27^{\circ} \mathrm{C}$, coefficients of convection transfer warmth for front and back surface was $6 \mathrm{~W} \mathrm{~m}^{-2} \mathrm{~K}^{-1}$. Thermal resistance for CFRP, Teflon film and Epoxy resin to calculate on the basis of material 


\section{http://dx.doi.org/10.21611/qirt.2006.076}

constants (table 2) and the geometrical parameters of structure (figure 4). Calculation of electrical model were performed for homogenous and multilayer structure with the following material constants (Figure 5, 6, 7).

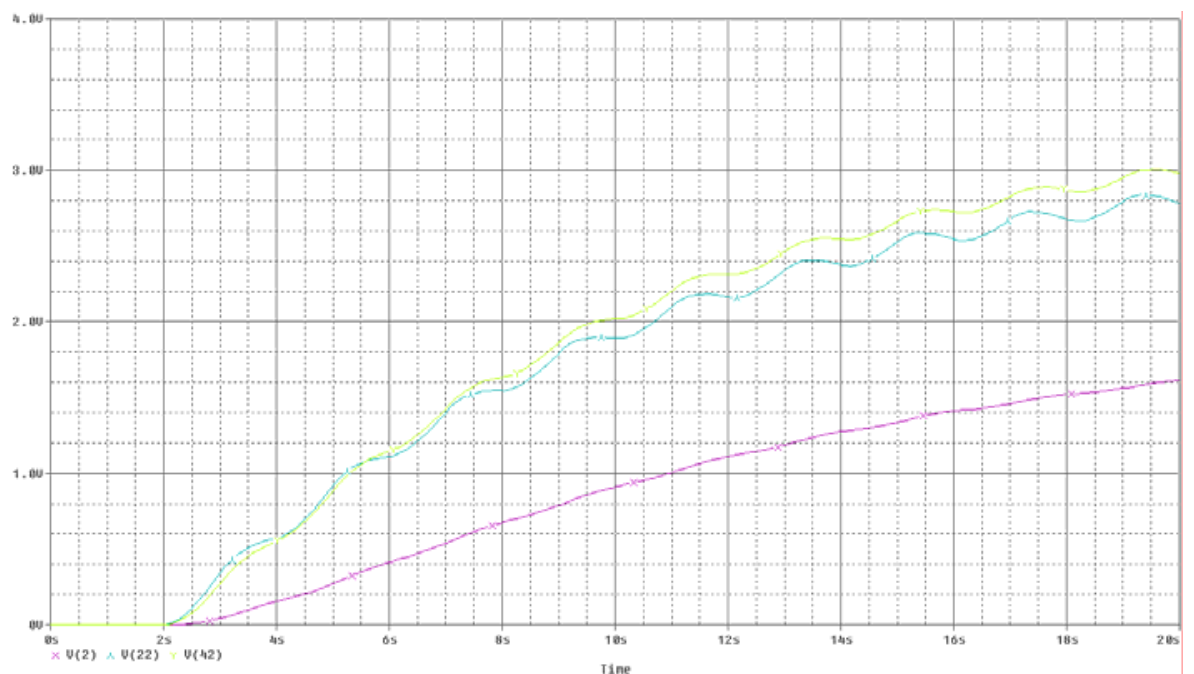

Fig. 5. Amlitude difference between materials: T(2) - CFRP, T(22) - Teflon film, $T(42)$ - Epoxy resin

The amplitude of signal for CFRP disappears, but for the other materials change of amplitude are identical (approximate material parameters, table 2).

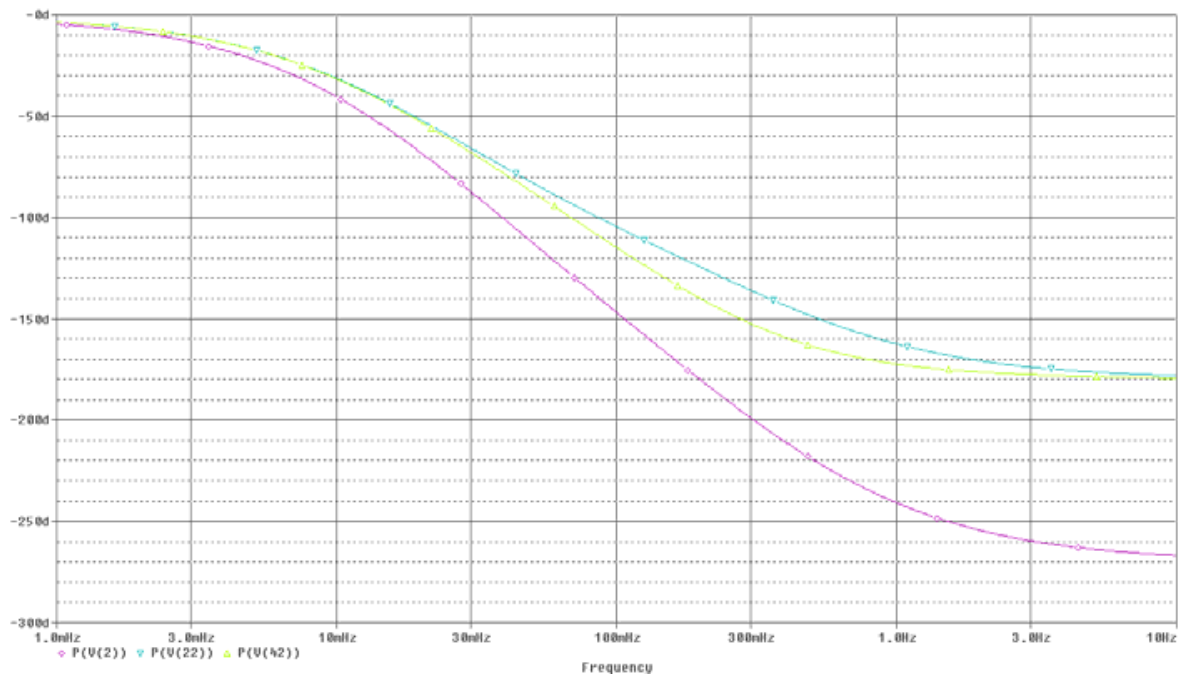

Fig. 6. Phase difference between materials: T(2) - CFRP, T(22) - Teflon film, T(42) Epoxy resin 
The difference phase is considerable for CFRP with reference to teflon film and epoxy resin. However the difference phase between teflon film and epoxy resin is insignificant (approximate material parameters, table 2).

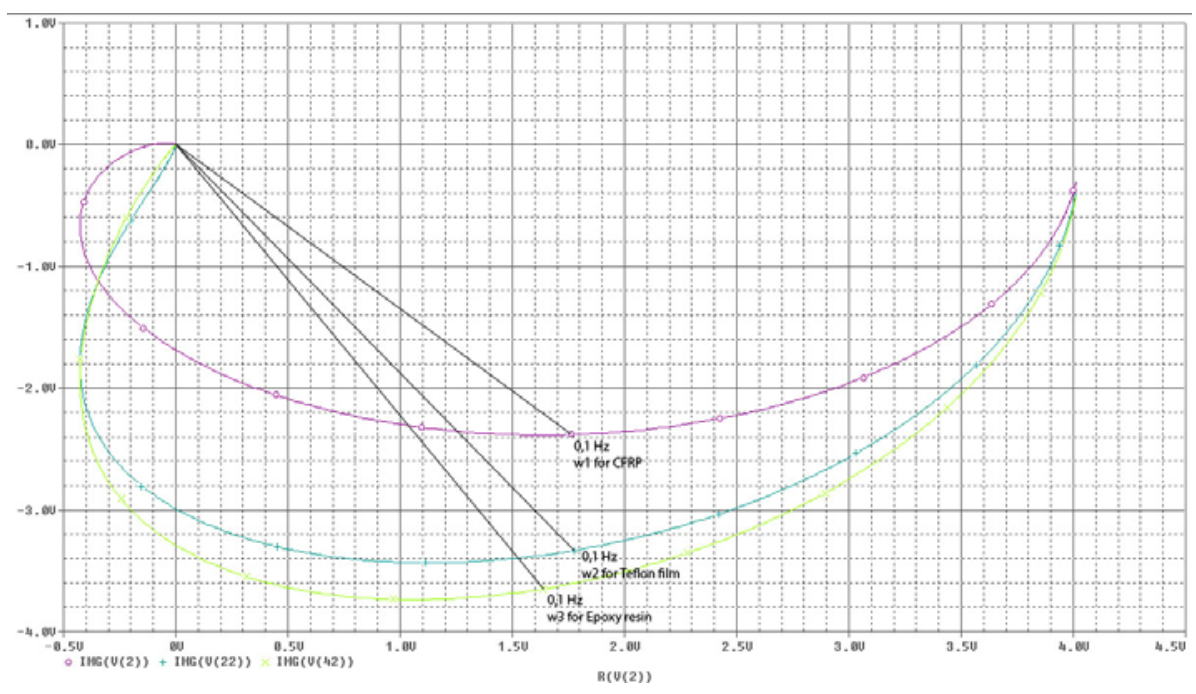

Fig. 7. Phasor diagram (Im-Re) for difference between materials: $T(2)-C F R P, T(22)$ - Teflon film, $T(42)$ - Epoxy resin

The Phasor diagram shows us the difference of angles $(\omega)$ for three materials. $\omega_{1}<\omega_{2}<\omega_{3}$ (CFRP $<$ Teflon film < Epoxy resin) so we can nominate materials with different thermal properties in complete structures.

\section{Conclusion}

In practical inspection, one should try to use optimum frequencies. The electrical models can approximately predict the result of the inspection. The model is very valuable for the selection of inspection parameters, which should result in great cost savings.

Heat transfer modeling proves the method potentialities for defect and multilayer structure measurements. Results obtained in this study confirm the thesis that electrical models are very useful to evaluate thermal properties of multilayer materials. Using temperature decay during cooling down process, or from the measurements phase difference we can nominate materials with different thermal properties, such thermal conductivity and diffusivity. Thermography investigations should be performed very carefully to reduce interference from elements having significant influence on the result e.g. mainly infrared reflection, non-stable conditions, undefined convective heat transfer coefficient, and so on. 
http://dx.doi.org/10.21611/qirt.2006.076

Tab. 3. Symbol index

\begin{tabular}{|c|l|}
\hline Symbol & Explanation \\
\hline$L$ & Thickness \\
\hline$q$ & Intensivity of the heat source \\
\hline$\omega$ & Angular modulation frequency \\
\hline$t$ & Time \\
\hline$k$ & Thermal conductivity \\
\hline$\rho$ & Density \\
\hline$C_{w}$ & Specific heat \\
\hline$T$ & The temperature \\
\hline$h$ & The surface heat transfer \\
\hline$R_{t h}$ & The thermal contact resistance \\
\hline$C_{t h}$ & The thermal capacity \\
\hline$V$ & volume \\
\hline$S$ & Surface \\
\hline$m$ & mass \\
\hline
\end{tabular}

\section{REFERENCES}

[1] Almond D. P., Lau C. K., Defect sizing by transient thermography, an analytical treatment, J. Phys. D: Appl. Phys., 27, 1994, pp.1063-1069.

[2] Almond D. P., Patel P. M., Photothermal science and techniques, London, Chapman \& Hall, 1996, pp. 108.

[3] Xavier P. V. Maldague., Theory and practice of infrared technology for nondestructive testing, Canada, John Wiley \& Sons, 2001.

[4] W. Bai, B. S. Wong, Evaluation of defects in composite plates under convective environments using lock-in thermography, Measurements Science and Technology, 12 (2001) 142-150.

[5] Nowakowski A. et al, Postęp termografii - aplikacje medyczne, Gdańsk 2001.

[6] B. Więcek, S. Zwolenik, Thermal wave method - limits and potentialities of active thermography in biology and medicine, 2nd Joint EMBS-BMES Conference, 24th Annual International Conference of the IEEE Engineering in Medicine and Biology Society, BMES-EMS 2002, Huston, 23-26 Oct. 2002.

[7] G. Gralewicz, G. Owczarek, B. Więcek; Investigations of Single and Multilayer Structures Using Lock-In Thermography - Possible Applications", International Journal of Occupational Safety and Ergonomics (JOSE) 2005, Vol. 11, No. 2, 211-215. 